\title{
Moral Testimony as Higher-Order Evidence
}

\author{
Marcus Lee, Jon Robson, and Neil Sinclair ${ }^{1}$
}

How should we respond to the moral testimony of others? In this chapter we explore the view that it is never reasonable to form moral judgements on the basis of the moral testimony of others, but it is sometimes reasonable to revise one's moral judgements on this basis. On the view we wish to explore, the former comes about because moral testimony cannot act as first-order evidence for forming moral judgements; the latter because such testimony can act as higher-order evidence for revising those same judgements. ${ }^{2}$ Hence, this view combines pessimism about the first-order evidential role of moral testimony with a cautiously non-sceptical view about its higher-order evidential role. After giving some considerations in favour of this moderate position, we explore the subsequent question: are the circumstances in which moral testimony serves as higher-order evidence the same sort of circumstances in which mundane (roughly, non-moral) testimony serves as higher-order evidence? Our tentative conclusion is that they are not and that this may put some pressure on the moderate view.

In $§ 1$ we distinguish two different roles that testimony might play: first-order and higher-order. The first of these (roughly) concerns the legitimacy of testimony as a source of judgement. The second (even more roughly) concerns the legitimacy of testimony as grounds for revising our judgements. One might think that if there is good reason to reject the former then there will be good reason to reject the latter (and it does seem that proponents of one sceptical view tend to endorse the other). ${ }^{3}$ However, in $\S 2$ we argue that the most prominent reasons for accepting pessimism concerning moral testimony in the literature would, even if cogent, provide no reason to reject the higher-order role of such testimony. In $\S 3$ we look in more detail at one particular strategy - appeals to considerations of autonomy - that we believe provides the best motivation for linking scepticism about the first- and higher-order roles. Even here, though, we argue that the connections are not straightforward. In $\$ 4$ we consider whether there are particular restrictions on the higher-order evidential role of moral testimony, and tentatively suggest some restrictions grounded in the often-observed practicality of morality. We also tentatively suggest that one of these strategies provides the most promising avenue for someone looking to reject the moderate view.

\footnotetext{
${ }^{1}$ Lead author: Marcus Lee. The other authors made equal contributions. Thanks to Marco Tiozzo, Kurt Sylvan, Javier González de Prado, Katherine Puddifoot, Daniel Whiting, Mona Simion, and all the other attendees of the University of Southampton Higher-Order Evidence Workshop on 25/04/19.

${ }^{2}$ We use 'evidence' here in a loose sense that is neutral both about whether testimony is ever strictly evidential as a source of judgement and about whether reasons for being sceptical about moral testimony are strictly evidential.

${ }^{3}$ E.g. Hills (2010: 219-30).
} 


\section{Two Roles for (Moral) Testimony}

Consider two types of case. In the first, we have no prior view on whether $p$ and receive testimony that $p$. In the second, we believe that not $p$ on the basis of evidence $\mathrm{E}$ but receive testimony that $p$ from someone with access to the same evidence. ${ }^{4}$ Further, assume that this someone is an epistemic peer in the narrow sense that there is no reason (antecedent to considering the question whether $p$ ) to think that either of us is any more reliable or competent with respect to $p$-like matters. ${ }^{5}$

The first kind of case (a 'first-order' case) concerns a paradigm case of testimony so needs no explication. By contrast, the second kind of case (a 'higher-order' case) requires unpacking. Suppose, for example, that Able and Mable are history professors who have read the same books, attended the same seminars, and so forth. On the basis of the arguments presented, Able has come to believe that Richard III killed the princes in the tower, and Mable has come to believe that Richard did no such thing (the arguments are complex and the issue difficult). Able says to Mable: 'Richard killed the princes in the tower', providing Mable with a piece of testimony that is contrary to her own judgement.

Note some general features of higher-order cases. First, they are cases where testimony is not the sole source of evidence. In Mable's case, she begins with some evidence that serves as the basis for her judgement. If it provides any evidence for anything at all, Able's testimony is evidence that is additional to this existing evidence. Second, the testimony provided in such cases (and, we will assume, in first-order cases) is pure in content. Able says: 'Richard killed the princes'. He does not say: 'We know that Richard killed the princes because ...' where the ellipses point to some further putative evidence of which Mable was previously unaware. ${ }^{6}$ Our focus here is on the evidential role of such 'pure' testimony. Third, although in the case of Able and Mable the latter receives testimony that is counter to her original judgement ('counter-testimony'), not all the cases with which we are concerned are like this. In a related case suppose that Babel is somewhat confident that Richard is guilty, but Able is absolutely adamant. Able says to Babel: 'Richard definitely killed the princes!' conveying as he does his absolute conviction in this matter. We are also concerned with the question whether it is now reasonable for Babel to be more confident about Richard's guilt.

Given these two kinds of cases, it seems there are at least two roles (moral) testimony might play. In the first, which we term the 'first-order role', testimony is providing a basis for forming a new judgement that $p .^{7}$ What precisely this basis is has been a source of much debate within the epistemology

\footnotetext{
${ }^{4}$ Cases of the kind we are concerned with are often invoked in discussions of the role of peer disagreement, however, it is worth noting that testimony of the relevant kind isn't necessary, and may not be sufficient, for generating peer disagreement. It is not necessary because an agent could learn of a peer's contradictory moral opinions by non-testimonial methods: their disapproving looks, examining scans of his brain, and so forth. It is (arguably) not sufficient owing to the existence of the kind of relativist view discussed in MacFarlane (2007).

${ }^{5}$ Kelly (2011: 183).

${ }^{6}$ See Hopkins (2011: 138), Hills (2010: 222), McGrath (2009), and Fritz (2018: 128).

${ }^{7} \mathrm{We}$ do not mean to suggest that these are the only first-order or higher-order roles which testimony might play but merely that these are the roles we will be focusing on. For example, testimony may also serve as a first-order
} 
of testimony but, for ease of exposition, we will here speak as if it is straightforwardly evidential. ${ }^{8}$ On this construal, in its first order-role, testimony provides evidence that $p$, where $p$ is the proposition (or one of the propositions) expressed by the content of the testimony.

The second role that testimony might play - the 'higher-order role' - does not involve taking testimony to bear directly on the issue of whether $p$, but instead involves taking the testimony to bear on the issue of whether one's initial response to the (first-order) evidence that $p$ was appropriate. ${ }^{9}$ To make this thought more accessible, consider Mable. Mable has looked at the evidence carefully and subsequently formed the judgement that Richard killed the princes. Able, who has seen the same evidence, testifies that Richard did not kill the Princes. Mable then reflects: Perhaps Able's testimony shows that my initial response to the evidence was misguided. And perhaps because of this I should lower my confidence that Richard killed the princes, or even suspend judgement on the matter altogether. More generally, to take testimony as higher-order evidence is to take that testimony to bear on the issue of whether one's response to the first-order evidence was appropriate. Where testimony plays this role, an appropriate response to it can be to alter one's confidence in an already-accepted proposition, or suspend judgement entirely. Simplifying somewhat, the higher-order role of testimony relates to revising one's judgements, where this covers - as we will discuss further below - both altering one's level of confidence and suspending judgement. This is the role of testimony in higher-order cases.

Two further points about the higher-order role are worth noting. First, considerations other than testimony can provide higher-order evidence. For example, evidence that one's judgement is subject to bias, that one has been slipped a smart drug (one that heightens reasoning abilities), or a belief pill (that makes you believe that $p$, independent of whether or not $p$ ) can also be higher-order evidence to revise one's judgement. (In ethics, some take evolutionary debunking arguments to be analogous to belief pill cases. ${ }^{10}$ ) Nevertheless, our focus is on a particular potential source of higher-order evidence, namely testimony. Second, it is worth noting that discussions of moral testimony have tended to focus exclusively on the first-order role. Indeed, the focus is often on cases where moral testimony is the only evidence that one has in such cases, which rules out any higher-order role.

When it comes to higher-order cases, the obvious question to ask is to what extent the new piece of testimony serves as higher-order evidence which should lead us to revise our judgement that $p$. Philosophers who have discussed higher-order cases have tended to agree that there are some cases in which testimony can play some legitimate higher-order role. Consider, for example, how strange it would be for someone who believed, on the basis of a quick calculation, that their share of the bill was

reason for revising your judgement in cases where you take the judgement your interlocutor is conveying to be based on first-order evidence which you haven't yourself assessed. Fletcher (2016 §2) labels this a type of 'indirect' reliance on testimony.

${ }^{8}$ For an overview see Lackey (2006).

${ }^{9}$ Compare Kelly (2011: 200).

${ }^{10}$ See Joyce (2007) and Sinclair (2018). 
$£ 17.88$ to refuse to lower their confidence at all when they learn that the other nine diners (all epistemic peers) conclude that it is $£ 17.99$. The question, then, tends to be about what role we should allow higherorder evidence to play. There are, however, a number of reasons for doubting whether this question will have a uniform answer. For example, Lackey (2010) has argued that the correct response is dependent on whether our initial judgement really was supported by the relevant evidence, and others argue that the correct answer varies depending on the domain under consideration. ${ }^{11}$ In this paper, we will investigate one possibility of this second kind by asking whether the circumstances in which moral testimony serves as higher-order evidence are the same circumstances in which mundane testimony serves a parallel role for mundane judgements. In doing so, we will assume that there are at least some mundane cases where testimony does provide higher-order evidence that should lead to our revising our judgements.

In the next two sections we consider arguments for a negative answer to our question based on pessimism concerning moral testimony. The suggestion is that the truth of pessimism clearly entails that moral testimony cannot play a higher-order role. We will argue that this is not the case since some of the most prominent reasons for accepting pessimism in the moral case provide no reason at all for a blanket rejection of the higher-order role of moral testimony (\$2). Other extant motivations for pessimism are more promising in this respect but still fall short of entailing that we must reject the higher-order role (\$3). We do, however, suggest $(\S 4)$ that there are some underexplored features of the moral domain which may justify both pessimism and scepticism concerning the higher-order role. Even here, though, the link between the two is by no means a straightforward one.

\section{Moral Testimony and the Norms of Moral Judgement}

Hopkins (2007) draws a distinction between two positions regarding the first-order role of moral testimony. Optimists think that there is in principle no special problem with relying on such testimony (as compared to cases of mundane testimony) as a (defeasible) source of first-order evidence for forming one's moral judgements, whereas pessimists think that though testimony is often a legitimate source of (defeasible) evidence in mundane cases, there is something in principle problematic about such reliance in the moral case. As we will see below, though, pessimists disagree in some significant respects about where the problem(s) lies here. In particular, some pessimists take the problem with such judgements to be a straightforwardly epistemic one whereas others take the difficult to be a moral, or otherwise non-epistemic one. It is also worth noting that both optimism and pessimism come in degrees. An extreme pessimist would claim that we can never legitimately form moral judgements on the basis of moral testimony. An extreme optimist would affirm that moral testimony is a legitimate basis on which

\footnotetext{
${ }^{11}$ E.g. McGonigal (2006) and Choo (2018).
} 
to form one's moral judgements about as often as it is in (some) mundane cases. There are also a range of positions one might hold between these two extremes, so it is better to think of there being a spectrum of views which tend towards optimism or pessimism, rather than a binary choice. ${ }^{12}$ Nonetheless, even if somewhat artificial, the distinction Hopkins sketches is a common and useful place to start. ${ }^{13}$

Since optimists think that there is no in principle difference between first-order reliance on moral testimony and reliance on testimony in mundane cases, it seems reasonable to assume they would have no in principle problem with reliance on moral testimony as higher-order evidence. ${ }^{14}$ This is not to suggest that they are unable to adopt scepticism about the higher-order role of moral testimony, but merely that their view concerning the first-order role of moral testimony does nothing to motivate it. The interesting question is whether pessimists who deny the first-order role of moral testimony have, qua pessimists, reason to doubt the legitimacy of testimony in the higher-order role. This is an underexplored question in the literature..$^{15}$

What pessimists think is problematic about relying on testimony in the first-order role varies. Here we will survey some of these reasons. Our concern is not to assess the plausibility of these explanations themselves but merely to ask whether, if cogent, they would also justify a rejection of the higher-order role. ${ }^{16}$

First, some suggest that pessimistic intuitions can be explained by the twin facts that (i) moral judgements are distinctively and intimately connected with affective responses ('moral sentiments'), such that moral judgements either cannot be formed in the absence of such responses, or are inappropriate in the absence of such responses, and (ii) such affective responses are difficult or impossible to form on the basis of testimony. ${ }^{17}$ Does this kind of pessimism transfer to the case of revising one's moral judgement on the basis of testimony considered as higher-order evidence? No. In higher-order cases, the agent has already formed a moral judgement that $p$ and, we can assume, done so in a way that satisfies the affective requirement. If they were to subsequently alter their credence in this judgement, or indeed abandon the initial judgement altogether, then this would not (provided they

\footnotetext{
${ }^{12}$ Robson (2012: 3-4) defends a view of this kind regarding parallel positions in aesthetics.

${ }^{13} \mathrm{We}$ will also talk as if the pessimist takes it to be impermissible to form moral judgements on the basis of testimony but it is worth noting that some pessimists only make the weaker claim that there is something problematic (or sub-optimal) about forming such judgements. See, e.g., Crisp (2014).

${ }^{14}$ Though they could appeal to in practice differences of the kind discussed in Elga (2007: 495-6).

${ }^{15}$ A recent exception is Fritz (2018) who asks a question which is distinct from, but closely related, to our own: whether pessimism about the first-order role supports steadfastness about moral disagreement (roughly, the view that disagreement in moral matters ought not affect our own judgements). His conclusion is that it does not. More precisely, he concludes that such pessimism does not rule out responding to disagreement by reducing one's confidence in, or suspending, one's judgements $(130,133-4)$, although it does undermine the practice of switching judgements in response to such disagreement $(129,133)$. Although we are generally sympathetic to Fritz's paper we think, as will become clear below, that he is rather too quick in his dismissal of autonomy arguments (125-6). Other minor disagreements, and differences in focus, should become clear below.

${ }^{16}$ This is a further contrast with Fritz (2018). The authors of this paper differ significantly in their assessments of the plausibility of these explanations (and of pessimism more generally).

${ }^{17}$ Fletcher $(2016 \S \S 4-5)$.
} 
don't take the further step of adopting the view of their opponent) involve introducing any new moral judgements whose status is open to suspicion. Therefore, the question of whether we can (legitimately) possess moral judgements in the absence of affective states is moot when it comes to determining the legitimacy of the higher-order role. Of course, we could make the further claim that it is illegitimate to alter our credence in a moral judgement without some corresponding alteration to our affective state but, crucially, this is an additional claim, one that isn't entailed by the initial claims that the affective pessimist makes. Further, it seems plausible to think that our affective states may well alter along with our credences. We may, for example, find ourselves becoming less resentful of a presumed enemy the less certain we become that they really have wronged us.

Parallel points seem to apply to other putative candidates for additional requirements on possessing moral judgements. Consider, for example, the influential view according to which moral testimony cannot play the first-order role since legitimate moral judgement requires moral understanding, where this is cashed out as having a 'grasp' of the relevant moral reasons. ${ }^{18}$ To explain: If an agent's moral judgment that $p$ is based on someone's testimony, then the reason for their believing $p$ is not the reason why $p$ is correct. For example, suppose Karen judges that euthanasia is (in some cases) morally permissible solely on the basis that her partner judges it so. The issue is that even if Karen's judgement is correct it is not based on considerations that underwrite its correctness; it is insensitive to the 'permissible-making' features of euthanasia. To gain understanding Karen would need to, inter alia, be capable of saying why these particular cases are morally permissible and what differentiates them from other, non-permissible, cases.

This motivation for pessimism could be put forward as the epistemic complaint that the agent lacks warrant for the judgement because moral testimony fails to provide moral understanding, and without moral understanding the agent does not know what the justificatory grounds for the judgement are. ${ }^{19}$ More commonly, however, concerns of this kind are phrased in terms of the agent's doing something morally (or otherwise non-epistemically) problematic in forming a moral judgement on the basis of testimony. ${ }^{20}$ For example, one common complaint is that without understanding the reasons for a moral judgement any actions performed on the basis of that judgement will be lacking in (full) moral worth. ${ }^{21}$

On this view, relying on testimony as the basis for moral judgments is problematic because of the tight link between moral judgement and action. The idea need not be that a moral judgement formed solely on the basis of moral testimony is problematic in itself, but that such judgement-formation becomes problematic given the practical nature of moral judgement. On this account morally worthy

\footnotetext{
${ }^{18}$ See Nickel (2001), Hopkins (2007), Hills (2009), and McGrath (2011).

${ }^{19}$ Cf. Nickel (2001).

${ }^{20}$ Of course, these two complaints are compatible.

${ }^{21}$ See Nickel (2001), Hills (2009), and McGrath (2011).
} 
action is the (or at least a) primary aim of moral judgement and any actions performed in the absence of moral understanding will fail to be (fully) morally worthy. As we might say, the ideally virtuous person not only does the right thing but does so for the very reasons that make it right. This is not necessarily to say that someone who does the right thing without knowing the reasons is blameworthy in that respect. Indeed, they could be praiseworthy to the extent that they did the right thing because it was the right thing. Nonetheless, according to this kind of pessimism, they still fall short of an important ethical ideal, and insofar as they do, their actions are lacking in moral worth.

Again, though, there seems to be no reason in all this to deny that moral testimony can play a higher-order role. The lack-of-moral-understanding explanation (along with various other pessimistic explanations of why moral testimony cannot legitimately play the first-order role) appeals to some additional norm of moral judgement such that forming (or sustaining) judgements on the basis of moral testimony inevitably leads to judgements that flout this norm. It is clear, though, that accepting pessimism about the first-order judgement-formation role is compatible with holding that moral testimony can legitimately perform a higher-order revising role. This is because revising one's level of confidence in a moral judgement, or suspending that judgement, does not in itself introduce any new moral judgement which is open to assessment on the basis of this additional norm. This is not, of course, to deny that revising one's credences might sometimes involve forming a new moral judgement but merely to insist that it doesn't always do so. We may, for example, move from believing that eating meat is morally wrong to being agnostic on this matter or retain the same judgement but with a reduced level of conviction. And we may do this while it remains the case that the relevant judgement was formed in such a way as to be accompanied by the appropriate affective responses or level of understanding. The overall message is that merely proposing some additional norm on moral judgement, a norm which some ways of forming moral judgements lead us to flout, provides no reason to deny that testimony can play a higher-order role, since a higher-order role concerns only the revision - and not the formation - of moral judgements. ${ }^{22}$

\section{Moral Testimony and Autonomy}

In the previous section we considered two prominent motivations for pessimism which, we argued, failed to provide clear grounds for rejecting the higher-order role of moral testimony. (Arguments which would also apply, mutatis mutandis, to many other forms of pessimism which are motivated by specific additional norms on moral judgement.) In this section, we look in more detail at a further motivation for pessimism that we take to represent the best prospect (amongst the arguments for pessimism which presently dominate the literature) for forging a link between a denial of the first-order role and a denial

${ }^{22}$ See Fritz (2018: 136). 
of the higher-order role: the connection between moral judgement and autonomy. One common criticism of reliance on moral testimony when forming moral judgements is that it involves a renunciation of one's autonomy. ${ }^{23}$ This account posits a norm applying directly to the formation of moral judgements. On this view, forming moral judgements in particular ways is problematic, not because the resulting judgements are themselves problematic (e.g., insofar as they lack affect or understanding), but because such judgement-forming processes are themselves objectionable, insofar as they are not autonomous (it is of course consistent with this that certain other processes concerning changes in judgement are similarly not autonomous). This is an important difference between the type of pessimism discussed in this section, and those discussed in $§ 2$.

If the worry concerning autonomy was only about a total outsourcing of moral decision-making to the kind of 'Google Morals' system described by Howell (2014) then this would provide scant reason to refrain from forming isolated moral judgements on the basis of testimony (and still less to avoid revising such judgements on that basis). However, many autonomy-based criticisms of relying on moral testimony are significantly more demanding than this. For example, Crisp (2014) suggests that there are some cases when reliance on moral testimony on just one occasion 'is detrimental to autonomy, unless we set the standards for rational self-government quite low' (2014: 138). The norm being flouted here is a moral (non-epistemic) norm on moral judgement formation qua autonomous action. There are, of course, various questions that could be raised concerning accounts of this kind. Why think that deferring to others in this way is especially autonomy-compromising? Why think that it is always or usually problematic to reduce our own autonomy? ${ }^{24}$ And so forth. Again, though, our concern won't be with evaluating this motivation for pessimism but asking whether, if cogent, it transfers to the higherorder case.

If all that is intended here is to introduce an additional non-epistemic (autonomy-based) norm on moral judgement-formation then this would fail to transfer to cases of moral judgement-revision for reasons paralleling those discussed in $\$ 2$ and more generally because the norms appropriate for one type of activity are not necessarily appropriate for a distinct type of activity. However, we think it is likely that those who have proposed a link between autonomy and pessimism take the demands of autonomy, as they relate to moral judgements, to be broader than this, covering other processes relating to moral judgement, such as their revision. Of course, if we merely stipulated that the species of autonomy at issue here required that we neither form nor revise moral judgements on the basis of testimony, then this would straightforwardly rule out the higher-order role as well. This would not, however, be of much theoretical interest. What we need, then, is a clearer explanation of the kind of autonomy involved here and the demands that it could make upon us.

\footnotetext{
${ }^{23}$ See Annas (2004) and Crisp (2014). Compare Sliwa (2012: 188-89).

${ }^{24}$ See Driver (2006: 636).
} 
As Driver (2006: 634) notes, autonomy is a 'murky' concept, involving many different elements that are easy to conflate. Here we will focus on the kind of autonomy she identifies that 'involves viewing the moral agent and the moral judge to be self-legislating in some sense'. Whether this kind of autonomy really rules out forming our moral judgements on the basis of testimony is, of course, controversial. ${ }^{25}$ But, once again, our concern won't be with evaluating the motivation itself but with asking whether, if cogent, it raises difficulty for the higher-order role. In order to examine this, consider the story that Crisp (2014: 136-7) offers concerning testimony in relation to autonomy of this kind according to which 'a person who accepts moral testimony is handing control over their moral sensibility to another, and hence implicitly surrendering their status as a freely thinking and autonomous agent'. ${ }^{26}$ Note three points about this account. First, it is not the (implausible) claim that someone who takes moral testimony ceases to be an autonomous agent altogether but, rather, that 'she fails to exercise her autonomy on this occasion, and in this sense her action is heteronomous and her life to that extent less autonomous overall' (2014: 137). Second, the decision to defer can itself be an autonomous one: 'heteronomy arises once the control has been transferred, not in the transference itself' (2014: 137). Third, Crisp's view is not the claim that relinquishing control of one's 'moral sensibility' in this way is, all things considered, always impermissible, but rather the claim that 'in certain cases, judging on the basis on the basis of testimony is always worse, to some degree, than judging for oneself, even though in those very cases, and indeed others, it may be better overall to rely on testimony' (2014: 141). Insofar as reliance on moral testimony is a failure to exercise one's autonomy on that occasion, the thought goes, such reliance is sub-optimal because reductions of autonomy are always pro tanto problematic.

There is much that needs to be said to fill out this account, but for our purposes this sketch should do. The key point is that in any instance where we opt for deference to someone else rather than exercising our own moral reasoning, we are making our lives less autonomous overall in a way which is pro tanto objectionable. ${ }^{27}$ Although Crisp (2014: 129) frames his account as a critique of the 'acquisition of moral beliefs through reliance on what others say' (that is, in terms of our first-order role) it is important to note that its consequences seem rather broader. It would, after all, seem strange for Crisp to hold that 'a person who accepts moral testimony is handing control over their moral sensibility to another' (2014: 136) in a way which problematically undermines their exercising autonomy but to deny that there are any autonomy-threatening consequences in someone's altering their confidence in an existing moral judgement on the basis of another's say so. This is not to say that such a position would be incoherent but merely that it fits very poorly with the general account of the nature

\footnotetext{
${ }^{25}$ Driver herself (2006: 635-6) raises some reasons for doubting that it does.

${ }^{26}$ Crisp (2014: 137-8) also discusses a second interpretation of autonomy-based requirements but we will focus here on the first.

${ }^{27}$ Crisp himself (2014: 138) takes this to be objectionable on both epistemic and moral grounds but other versions of this account might focus on one of these at the expense of the other.
} 
and value of autonomy that Crisp proposes. The requirement to be autonomous with respect to our 'moral sensibility' seems much wider than merely the requirement not to defer to the testimony of others when forming moral judgements.

Here, then, we have an account of the importance of autonomy which could be used to motivate scepticism about the formation and revision of our moral judgements on the basis of testimony in certain cases. It is important, though, to stress the difference between two kinds of moral judgement revision. In the first kind of case someone might revise their moral judgements on the basis of first-order considerations (for example, if they receive testimony from someone who has, or who they take to have, access to relevant evidence which they lack). This kind of judgement revision is plausibly ruled out by the autonomy-based considerations noted above; but it isn't the kind of (higher-order) case we are focusing on in this paper. By contrast, it is by no means clear that considerations of autonomy do anything to undermine the higher-order motivation for judgement revision.

Consider, again, one kind of judgment revision we have been focusing on: where an agent reduces her credence in her moral judgement that $p$ upon hearing testimony that not $p$, because she takes the testimony as (defeasible) evidence that her own judgement-forming capacity is misfiring on this occasion (that is, the testimony is playing a higher-order role). In this case, the immediate target of higher-order evidence isn't any kind of moral judgement but, rather, the agent's judgements concerning the reliability of her own cognitive faculties. And it is perfectly consistent to propose a very strong requirement for self-legislation in the moral domain - one which refuses to allow the testimony of others to legitimately make even the smallest direct impact on our moral judgements - while still allowing that the testimony of others can provide very good reasons to doubt the reliability of our own judgmentforming mechanisms (including those we use to form our moral judgements). Indeed, being sensitive to the reliability of one's judgement forming-mechanisms could be argued to be a paradigm of reflective, autonomous, agency (as opposed to being blindly led by one's unexamined judgementforming habits).

Further, any autonomy requirement which entailed that we can never legitimately accept a judgement on the basis of testimony, where that judgement then leads (via a fairly straightforward route) to the legitimate revision of a moral judgement, would be manifestly implausible. Imagine, for example, that Poppy judges that it is wrong to eat fish and judges this way solely on the basis of the pain that this causes to the individual fish involved. She is then told by a reliable source that, owing to new evidence, there is now a consensus amongst experts that fish don't feel pain. It seems clear that she should now abandon her previous moral judgement based on this (non-moral) testimony - yet this hardly strikes against Poppy's autonomy. Indeed, responding for oneself to new information such as this seems to be paradigm case of autonomous judgement formation (as opposed, for instance, to being 'goaded' into accepting a view on the basis of threats or propaganda which obscure the facts). Nor is it the case that 
we can reasonably hold that testimony can never serve as higher-order evidence concerning our moral judgements. Consider a case where you are told (again via impeccably reliable testimony) that the last time you formed a moral judgement on the basis of your own reasoning you were under the influence of some introspectively undetectable drug that severely compromises reasoning (moral or otherwise) ${ }^{28}$ It seems clear that this information should, at the very least, lead you to become significantly less confident in that judgement (and again, doing so seems to be an affirmation of autonomy, rather than a degradation of it). All of this is not, of course, to deny that there could be some way to motivate a form of autonomy in moral judgement which ruled out the particular kind of higher-order role we are considering. Rather, our claim is merely that work needs to be done to show why any independently plausible version of the autonomy requirement would have this consequence.

\section{A Practical Reason for Rejecting the Higher-Order Role}

The foregoing suggests that there is no general reason to be pessimistic about the higher-order role of moral testimony. Relying on such testimony to revise one's moral judgements does not undermine any affective basis that legitimate moral judgements might have, nor does it undermine moral understanding or agential autonomy. Or, more precisely, if reliance on moral testimony is problematic in any of these ways then this would need a novel argument, independent of standard pessimistic concerns. This seems to raise two question: (i) are there any circumstances in which we should not grant moral testimony a higher-order role? (ii) If so, does the best explanation for this also provide a motivation for pessimism?

Many philosophers have addressed the more general question: are there any circumstances in which we should not grant testimony - any testimony - a higher-order role? Kelly (2011) gives several plausible examples of circumstances that disqualify testimony from playing any higher-order role. For example, we should not grant testimony a higher-order role if that testimony is not independent of some other testimony that one has already considered. ${ }^{29}$ Nor should we grant testimony a higher-order role if there is compelling evidence that, in the case at hand, one's peer has not responded appropriately to the evidence you share (for example, if they have arrived at an obviously false judgement on the basis of that evidence), or, in related cases, when the agent possesses compelling evidence that she herself has responded entirely appropriately to the first-order evidence. ${ }^{30}$ These conditions apply equally to moral and non-moral cases: for example, even in moral matters, the number of people providing additional testimony is largely irrelevant if they are not independent of each other.

\footnotetext{
${ }^{28}$ This case is similar to the one described in Christensen (2011: 6-7).

29 '...numbers mean little in the absence of independence...' - Kelly (2011: 204-5). Though see Coady (2006) for some exceptions to this general claim.

${ }^{30}$ Kelly (2010: 207-208).
} 
Doubtless there are other cases where (almost) everyone would agree that no revision is in order, regardless of the domain. The relevant question here is whether there are any circumstances particular to the moral case that undermine the higher-order role of testimony?

One possibility concerns viciousness. Suppose one's peer is generally reliable on moral matters - their moral judgements are reliably accurate. But they are also, to use a piece of technical terminology, a bastard. They are a bastard, not because they think (for example) that the only duties that exist are duties to oneself - in that case their moral judgements would not be reliably accurate - but rather because although they generally make the correct moral judgements (that one ought, ceteris paribus, to keep promises, pay debts, not cause harm, and so on) they systematically fail to live up to them. (Naturally, for us to have reason to trust their testimony we would need to stipulate that, for whatever reason, they make an exception to their bastardly behaviour when it comes to truth telling.) There is no non-moral (or at least non-normative) correlate of the moral bastard - their bastardy is defined in terms of making a set of (reliably correct) normative judgements, but then not living up to the way that those judgements prescribe or recommend. If a set of judgements do not have normative content, they do not prescribe or recommend, and therefore cannot be contradicted in action in this way. Therefore, if moral bastardy rules out moral testimony playing a higher-order role, this is not a restriction that transfers to mundane non-moral (or non-normative) cases.

And, intuitively, moral bastardy does undermine (or at least diminish) any higher-order role of moral testimony. ${ }^{31}$ Consider Sally the saint and Bertie the bastard. Both are equally reliable in their moral judgements, but only the former acts appropriately in light of those judgements. Suppose that we judge that eating meat is morally permissible. Both Sally and Bertie demur, and testify: 'Eating meat is wrong' (assume we share the same first-order evidence). Sally lives up to her testimonial judgement, and assiduously refrains from eating meat. Bertie, on the other hand, only eats steak and invests all his spare money in factory farming ('What do I care for morality?' he adds). Intuitively, Sally's testimony should weigh with us more than Bertie's. In particular the fact that Sally has considered the same evidence as we have, and yet has come to a contrary conclusion on the basis of that evidence, should (other things being equal) be treated as higher-order evidence that our initial response to the first-order evidence was not appropriate, and hence cause us to revise our judgement that eating meat is morally permissible. But Bertie's counter-testimony should, intuitively at least, not be given the same (higherorder) evidential weight - because Bertie is a bastard. ${ }^{32}$ Somewhat less intuitively but still plausibly,

\footnotetext{
${ }^{31}$ See, e.g., Annas (2004: 64).

${ }^{32}$ We take this intuition to widely, but by no means universally, shared (for example, a referee reports not sharing it).
} 
Bertie's testimony should be given no (higher-order) evidential weight at all - again because Bertie is a bastard. In a slogan: don't let the bastards get you(r moral credences) down! ${ }^{33}$

These are just intuitions, of course. But if correct, they suggest that there are particularly moral conditions on whether moral testimony should be given higher-order evidential weight. If they are incorrect, they need to be explained away. By contrast, if the issue is non-moral (or non-normative) for example about the division of a restaurant bill - whether or not one's peer is a moral bastard, again assuming they're the honest kind, seems irrelevant to the higher-order evidential weight one should afford their testimony. Similarly, even in the case of moral judgements, it seems crucial that the testimony has moral content. There is, in our view at least, nothing intuitively problematic about reducing your confidence in the claim that eating meat is permissible based on testimony from a(n honest) bastard, where that testimony is to the effect that you've ingested a pill that compromises your ability to reliably form moral judgements.

Can we move beyond bare intuitions and provide theoretical grounding for the claim that moral bastardy undermines the higher-order evidential role of moral testimony? The next few paragraphs explore two putative grounds.

The first is as follows. Quite generally, insincere or confused testimony should not be given higher-order evidential weight. Return to the example of Able and Mable. If Mable discovers that Able's counter-testimony is insincere, or that Able doesn't really understand what the words 'princes' or 'tower' mean, then the testimony provides no reason for Mable to revise her judgement that Richard III did not kill the princes. Moreover - this view continues - in the case of moral judgements (and only that case) being appropriately motivated is a sincerity or competence condition for moral judgement: an agent who (apparently) judges that $\phi$ is wrong, for instance, and yet is not in some way motivated against ping, thereby reveals themselves to be insincere or confused about the meaning of the term 'wrong'. ${ }^{34}$ The argument then is that insincerity or semantic incompetence is in general a disqualifying condition for testimony playing a higher-order role. And since in the moral case insincerity or semantic incompetence follows from a lack of appropriate motivation, it follows that in the moral case lack of appropriate motivation is a disqualifying condition for testimony playing a higher-order role.

However, this is a treacherous argument because it is not clear that being appropriately motivated is a sincerity or competence condition for moral judgement. As Brink has argued, amoralists - agents who sincerely make moral judgements but are not appropriately motivated - seem to be a conceptual possibility. ${ }^{35}$ Moreover, arguments for thinking that such agents cannot be competent with

\footnotetext{
33 One suggestion, which we won't explore here, might be that our contempt for such people makes us psychologically incapable of taking their testimony as reason to alter our credences in the relevant way (compare to DiPaolo (this volume) on the inability of certain 'fanatics' to respond to disagreement).

${ }^{34}$ See Smith (1994).

${ }^{35}$ Brink (1989: ch. 3).
} 
the moral terms they deploy - such as Smith's fetishism argument - have generally failed. ${ }^{36}$ Further, it doesn't seem particularly relevant that our bastard feels no motivation to act morally. There would also be something intuitively problematic about testimony from someone who experiences some (minimal) motivation to act morally but consistently experiences stronger motivation in the other direction (on the basis of self-interest, sadism or what have you). ${ }^{37}$ It is worth considering, then, alternative groundings for the intuition that one should not give any higher-order evidential role to the moral testimony of bastards, which brings us to our second suggestion.

The 'internalist' idea that moral judgements are necessarily connected to appropriate motivational states is one way of cashing out the thought that morality is practical. But there are other ways of cashing out this thought, which might do better in explaining the intuitions at stake. Suppose, for example, that one goal of moral inquiry is interpersonal action-alignment, i.e. not just for you personally to come to the correct moral judgements, but for you and your fellow enquirers to act rightly in light of these judgements (that is, for not merely your collective judgements, but your collective actions, to align with the moral facts - this is the distinctive interpersonal normativity of morality). Moral inquiry would not be over - moral matters would not be settled - if everyone professed the same moral judgements, but some consistently acted contrary to those judgements. ${ }^{38}$ Then, forming moral judgements on the basis of pure testimony from bastards would not meet this goal, ${ }^{39}$ so would be inappropriate - the hypothesised goal of moral inquiry explains the norm relating to the formation of judgements that are the product of that inquiry. This reason for not relying on the testimony of bastards in forming moral judgements is easily overlooked however, because forming moral judgements on the testimony of anyone seems to many to undermine other important goals of moral inquiry and judgement - such as moral understanding or autonomy - that are sufficient to make this kind of deference dubious.

However, while we have suggested above that these other goals aren't (obviously) compromised by revising our moral judgements based on the testimony of others, it does seem problematic to revise these judgements on the basis of the testimony of bastards (i.e., to give such testimony a higher-order role). This is because allowing their testimony to play the higher order role would, again, fail to advance the goal of interpersonal action-alignment (in a way that revising moral judgements in response to the testimony of bastards need not fail to advance other goals of moral inquiry - see e.g. Fritz 2018: 131). Suppose, for example, that in response to Bertie's testimony that eating meat is wrong we revise downwards our credence that eating meat is permissible or suspend judgement on

\footnotetext{
${ }^{36}$ See Lillehammer (1997).

${ }^{37}$ Further, this explanation doesn't seem to vindicate the claim that there is something exceptional about moral testimony (since we should be suspicious of testimony in any domain from those who lack either sincerity or competence in that domain).

${ }^{38}$ By contrast, non-moral inquiry would be over once the judgements were settled - see Stevenson (1963). This does not entail that moral inquiry possesses mechanisms that guarantee that all moral matters can be settled.

${ }^{39}$ Either because one was oneself a bastard, in which case neither of your actions are aligned with the moral facts, or because you are not a bastard, in which case although your actions so align, the bastard's do not.
} 
the matter entirely. This might make us slightly more reluctant to eat meat, so we eat less. Bertie, on the other hand, continues to judge that eating meat is wrong, and continues to scarf the stuff. In no sense has this change furthered the goal of interpersonal action-alignment. By contrast, responding in the same way to Sally's saintly testimony does seem to further this goal. So in the moral case, not only does forming judgements on the basis of the testimony of bastards not meet (or further) this goal of moral inquiry, revising judgements on the basis of bastardly testimony does not do so either. ${ }^{40}$ This is why the latter is problematic. And problematic in the way that relates to the distinctive practical nature of morality, and to the essence of moral bastardy, neither of which has an analogue in non-moral cases. It is this account, we suggest, which offers the most promising link between pessimism and rejecting moral testimony's higher-order role. As it stands, though, this explanation is rather underdeveloped and so it would be premature to make any definitive judgements as to its success in justifying either pessimism or scepticism concerning-the higher order role of moral testimony (and even more so about its ability to link the two).

\section{Conclusion}

If the tentative explanation we offered in the previous section is correct, then we can explain the distinctive epistemic restrictions on the higher-order role of moral testimony in part in terms of the distinctive, practical, action-guiding, goals of moral inquiry and judgement. ${ }^{41}$ In one sense, this is surprising, since it seems to derive 'oughts' from social and psychological 'ises' (concerning the aims or goals of moral inquiry). But in another sense, it is not surprising at all, since it is only by understanding the distinctive functions of the practices of forming and - for this may be distinct revising moral judgements that we can understand the norms appropriate to those practices (the same applies, of course, to judgements of other types, such as those of beauty or taste). It may be that one underestimates those distinctive functions if one holds (as some versions of moral realism seem to) that the goal of such practices is simply to 'see matters aright' and then to transmit that knowledge. In this sense, the arguments of this paper are consonant with those of Hills and others, who have suggested that a more developed and nuanced account of the aims of moral inquiry may be key to explaining the permissible moves within it. Our approach is different only insofar as the relevant goals proposed are collective, rather than individualist.

\footnotetext{
${ }^{40}$ The same applies, mutatis mutandis, for suspending moral judgements.

${ }^{41}$ It follows that theories of the nature of moral inquiry and judgement that deny practicality cannot in this way explain the intuitive restrictions on the higher-order role of moral testimony. It is an interesting question whether this explanation extends to other normative judgements, such as aesthetic and prudential judgements. It seems to us that while such judgements are practical (or normative), they are not practical in precisely the same way as moral judgements, so it is not obvious that their practicality can similarly explain any analogous restrictions.
} 
References

Annas, J. (2004). Being virtuous and doing the right thing. Proceedings and addresses of the American philosophical association, 78(2), 61-75.

Brink, D. (1989). Moral Realism and the Foundations of Ethics. Cambridge: Cambridge University Press.

Christensen, D. (2011). Disagreement, question-begging, and epistemic self-criticism. Philosophers' Imprint, 11(6), 1-22.

Choo, F. (2018). The Epistemic Significance of Religious Disagreements: Cases of Unconfirmed Superiority Disagreements. Topoi, 1-9.

Coady, D. (2006). When experts disagree. Episteme, 3(1-2), 68-79.

Crisp, R. (2014). Moral Testimony Pessimism: A Defence. Aristotelian Society Supplementary Volume, $88(1), 129-143$.

Driver, J. (2006). Autonomy and the asymmetry problem for moral expertise. Philosophical Studies, $128(3), 619-644$.

Elga, A. (2007). Reflection and disagreement. Noûs, 41(3), 478-502.

Fletcher, G. (2016). Moral Testimony: Once More with Feeling. Oxford Studies in Metaethics, 11. 4573.

Fritz, J. (2018). What Pessimism about Moral Deference Means for Disagreement. Ethical Theory and Moral Practice, 21(1), 121-136.

Hills, A. (2009). Moral testimony and moral epistemology. Ethics, 120(1), 94-127.

--. The Beloved Self. Oxford: Oxford University Press.

Howell, R. J. (2014). Google morals, virtue, and the asymmetry of deference. Noûs, 48(3), 389-415.

Hopkins, R. (2007). What is wrong with moral testimony? Philosophy and Phenomenological Research, 74(3), 611-634.

--. (2011). How to be a pessimist about aesthetic testimony. The Journal of Philosophy, 108(3), 138157.

Joyce, R. (2007). The evolution of morality. Cambridge MA.: MIT press. 
Kelly, T. (2010). Peer Disagreement and Higher Order Evidence. In A. Goldman and D. Whitcomb (eds.) Social Epistemology: Essential Readings. Oxford: Oxford University Press. 183-217.

Lackey, J. (2006). Knowing from testimony. Philosophy Compass, 1(5), 432-448.

--. (2010). A Justificationist View of Disagreement's Epistemic Significance. In A. Haddock, A. Millar and D. Pritchard (eds.) Social Epistemology. Oxford: Oxford University Press. 298-325.

McGonigal, A. (2006). The autonomy of aesthetic judgement. The British Journal of Aesthetics, 46(4), 331-348.

Lillehammer, H. (1997). Smith on Moral Fetishism. Analysis 57: 187-195.

MacFarlane, J. (2007). Relativism and disagreement. Philosophical Studies, 132(1), 17-31.

McGrath, S. (2009). The puzzle of pure moral deference. Philosophical Perspectives 23(1), 321-344

--. (2011). Skepticism about moral expertise as a puzzle for moral realism. The Journal of Philosophy, 108(3), 111-137.

Nickel, P. (2001). Moral testimony and its authority. Ethical Theory and Moral Practice, 4(3), 253266.

Robson, J. (2012). Aesthetic testimony. Philosophy Compass, 7(1), 1-10.

Sinclair, N. (2018). Belief Pills and the Possibility of Moral Epistemology. Oxford Studies in Metaethics, 13, 98-122

Sliwa, P. (2012). In defense of moral testimony. Philosophical Studies, 158(2), 175-195.

Smith, M. (1994). The Moral Problem. Oxford: Blackwell.

Stevenson, C.L. (1963). 'The Nature of Ethical Disagreement' in his Facts and Values. New Haven: Yale University Press. 